NASA Technical Memorandum 87266

\title{
Fracture Characteristics of Angleplied Laminates Fabricated From Overaged Graphite/Epoxy Prepreg
}

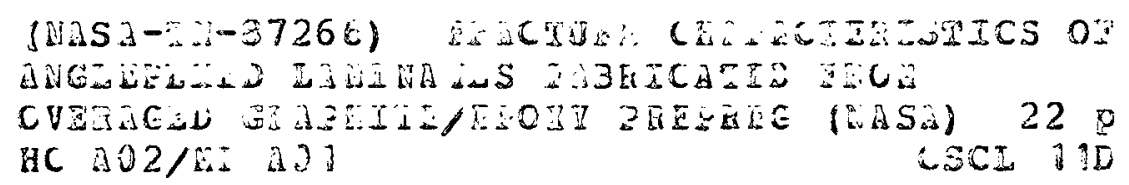

Carol A. Ginty and Christos C. Chamis

\section{Lewis Research Center}

Cleveland, Ohio

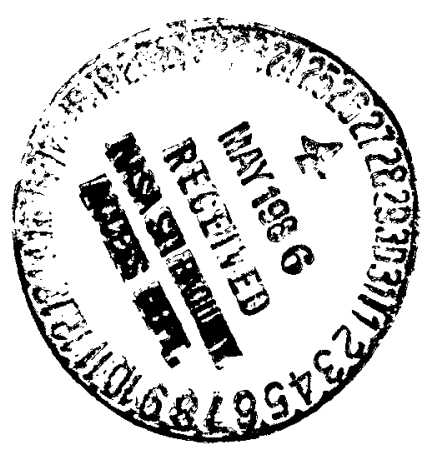

Prepared for the Symposium on Fractography of Modern Engineering Materials sponsored by the American Society for Testing and Materials Nashville, Tennessee, November 18-19, 1985 
FRACTURE CHARACTERISIICS OF ,ANGLEPLIED LAMINATES FABRICAIEU

FROM OVERAGED GRAPHITE/EPOXY PREPREG

Carol A. Ginty* and Christos C. Chamis**

National Aeronautics and Space Administration

Lewis Research Center

Cleveland, Ohio 44135

\section{SUMMARY}

A series of angleplied graphite/epoxy laminates was fabricated from overaged prepreg and tested in tension to investigate the effects of overaged or "advanced-cure" material on the degradation of laminate strength. Results which include fracture stresses indicate a severe degradation in strength. In addition the fracture surfaces and microstructural characteristics are distinctly unlike any features observed in previous tests of this prepreg and laminate configuration. Photographs of the surfaces and microstructures-reveal flat morphologies consisting of alternate rows of fibers and hackles. These fracture surface characteristics are independent of the laminate configurations. The photomicrographs are presented and compared with data from similar. studies to show the unfque characteristics produced by the overaged prepreg. Analytical studies produced results which agreed with those from the experimen-tal investigations.

\section{INTROOUCIION}

Graphite epoxy composites are commonly used in the design and manufacture of components for both aeronautical and space structures. Understanding the fracture modes in these graphite-epoxy composites is very important since many of these structures are primary load bearing components in the design.

NASA Lewis has developed an integrated program, Composite fracture characterization, that incorporates analytical, experimental, and, post.failure analysis techniques, to study the progressive fracture of fiber composites. Various factors contribute to the damage in fiber composites and therefore affect the progressive fracture. Factors such as laminate thickness, ply configuration, notch sensitivity, and notch-type sensitivity have been included in the program. Early studies on progressive fracture concentrated on a series of four ply, angleplied $[ \pm \theta]_{S}$ laminates. Both unnotched and notched (slits and holes) laminates have been tested in uniaxial tension to fracture. In conjunction with the experimental. investigation, analytical methods incorporated into in-house computer codes were used to predict progressive damage. The integrated approach used in this program as well as the experimental and analytical results are shown and discussed in. reference 1 . More detalled results generated from those-studies. including fracture surface characteristics of notched angleplied laminates (ref. 2) and related fracture modes in notched angleplied laminates (ref. 3). have been published. Significant results from.

* Aerospace Structures Engineer.

**Senior Research Engineer Aerospace Structures/Composites. 
these early studies show that: (1) unique microstructural characteristics exist for each angle-ply orientation, (2) microstructural characteristics can be used as criteria by which to determine accompanying fracture modes, and (3) the predominant fracture mode and thereby the fracture surface characteristics are a function of the ply angle orientation.

All laminates for the work reported here in were fabricated from Fiberite 1034 prepreg (934 resin impregnated with Thornel 300 graphite fibers) which is the same material used previously (ref's: 1 to 3 ). The material was delivered and stored on a roll at $0^{\circ} \mathrm{F}$ as recommended by the manufacturer's data sheet to insure a 6-month rated shelf life. The specimen's fabrication and test dates are randomly selected due to the dynamic nature of the composites program. Thus, experience has demonstrated that this prepreg usually meets or surpasses the material properties provided by the manufacturer even after its rated shelf. life has been exceeded. "Fracture strengths published in references 1 to 3 do not reflect any degradation and likewise, similar fracture surface characteristics were observed from 6 month old prepreg, 1 yr old prepreg, and even 2 yr old prepreg.

Recently, there has been considerable interest in post-mortem analysis of in-service failures of composite structures based upon their fracture surface: characteristics. It is also known that in-service composite structures may undergo the phenomenon of "advanced-cure,". whereby the properties of the resin change due to a chemical reaction in an uncontrolled environment. This phenom. enon of "advanced-cure" can be initiated by several factors: the thermal and - hygral environments as well as the state or condition of the prepreg itself.

While information is limited on the "advanced-cure" of composites and pos. sible subsequent degradation, Clements, in reference 4 , discovered that in a $0^{\circ}$ laminate, moisture was found to produce an apparent weakening of the inter-. facial bond. In addition, she reported that when both temperature and moisture content are increased, the interfacial bond is considerably weakened and the epoxy becomes more brittle, breaking up and falling away from the filaments. A study on the failure morphologies of these "elevated temperature wet" specimens suggests a drop in strength.

Clements with Adamson also reported (ref. 5) that a reduction in the glass transition temperature might lead to physical aging of an epoxy which would produce epoxy embrittlement. The graphite-epoxy prepreg on-hand, having been. stored at $0{ }^{\circ} \mathrm{F}$, had physically aged by the passage of time (approx 3.5 yr) and will' now be referred to throughout as overaged prepreg. . Since overaged prepreg is one form of "advanced cure," specimens were fabricated and tested from the available prepreg to (1) determine possible fracture stress degradation, and (2) examine the attendant fracture surface characteristics.

The overaged prepreg specimens were fabricated in a $\left[+\theta_{2}\right]_{s}$ configuration, to permit direct comparison of the fracture stresses and the fracture surface characteristics associated with the overaged prepreg to those from the earlier studies (refs. 1 to 3 ) which involved the same batch of prepreg at a-younger age. Results of the comparison would immediately indicate any degradation in strength and the effect of the "advanced-cure" on the microstructure. In addition, specimens were also fabricated from a newly purchased (fresh) batch of prepreg and five replicates of each configuration $\left(\left[+\theta_{2}\right]_{5}\right)$ were tested. The tensile strength results from these fresh prepreg laminates were also 
compared to those from the overaged prepreg to determine the severity of degradation in laminate strength for this particular configuration.

Results including fracture stresses, physical fracture characteristics, and microstructural features are presented and compared for: (1) laminates fabricated from a good batch of prepreg in previous studies, (2) laminates fabricated from the same batch of prepreg in, an overaged state, and (3) laminates fabricated from a fresh batch of prepreg.

\section{CHARACTERISTICS OF $[ \pm \theta]_{S}$ LAMINAIES}

The effect of ply orientation on the progressive fracture of $[ \pm \theta]_{s}$ laminates constituted one phase of the Composite fracture Characterization program mentioned above. A series of four-ply laminates was fabricated from graphite/epoxy prepreg with $\theta=0^{\circ}, 3^{\circ}, 5^{\circ}, 10^{\circ}, 15^{\circ}, 30^{\circ}, 45^{\circ}, 60^{\circ}, 75^{\circ}$, and $90^{\circ}$. (The same fabrication process was used for all of the laminates discussed. The curing cycle consists of: (1) heating the molded laminate to 350 of at a $5^{\circ} \mathrm{F} / \mathrm{min}$ rate, (2) applying a pressure of $100 \mathrm{psi}\left(0.689 \mathrm{~N} / \mathrm{mm}^{2}\right)$ for $2 \mathrm{hr}$, (3) cooling the laminate under pressure to about $150^{\circ} \mathrm{F}$, and (4) removing the laminate from the molds.) For each ply configuration, three specimens were tested in tension. One specimen was unnotched and the other two contained through-the-thickness notches to investigate composite notch sensitivity. To determine the effect, if any, of notch type, both a slit and hole were utilized. (See ref. 1 for details on notch geometry.)

Four angleplied configurations were selected for comparison and discussion: $[0]_{4},[ \pm 15]_{S},[ \pm 30]_{S}$, and $[ \pm 45]_{s}$. Each laminate's performance is described in terms of fracture stress, physical fracture characteristics, and microstructural features. The information gathered from these laminates which were fabricated from a good batch of prepreg will serve as a baseline for the comparisons to be made later.

The fracture stresses shown in table $l$ for these select laminates were obtained by incrementally loading the specimens in uniaxial tension to fracture. All photomicrographs presented herein document the microscopic investi. gation conducted with an Amray 1200 Scanning Electron Microscope (SEM). All SEM specimens were coated with a $200 \AA$ thick gold film to enhance the conductivity of the specimen thereby improving transmission of the SEM.

The fracture characteristics of the $[0]_{4}$ specimens are shown in $\mathrm{fig}$ ure 1. The laminate experienced a catastrophic fracture, leaving very little of the specimen intact. The dominant microstructural characteristic on the fracture surface is the tiered fibers resulting from fibers breaking at various locations along their lengths. The photomicrographs show that the tiered fiber surfaces are clean and free of matrix residue, indicative of debonding between the fiber and matrix.

Figure 2 displays the fracture surfaces of the $[ \pm 15]_{5}$ laminates. The laminate fracture occurred across the widths of the specimens. For the notched specimens, the fracture progressed through the notch. itself. Analysis of the photomicrographs revealed an irregular fracture morphology consisting of broken fibers, fiber pull-out, and some matrix hackles. 
The fractures of the $[ \pm 30]_{s}$ specimens also occur through the notches and across the widths as shown in figure 3 . Both the inner $(-30)$ plies and outer $(+30)$ plies exhibit fiber pull-out and fiber breakage in different locations: The morphology for the $[ \pm 30]_{5}$ laminate is irregular and similar to that observed for the $[ \pm 15]_{s}$ laminate.

In figure 4 , the $[ \pm 45]_{s}$ specimens fractured along a plane parallel to the fiber direction and through the notches. The morphology consists of a flat surface on the outer plies which exhibit an extensive amount of hackles in contrast to the irregular surface on the inner plies which experience pulled-out fibers.

These fracture characteristics have been documented for the purpose of comparison and therefore have been depicted somewhat "generically." Details of these studies and resulting conclusions are published in references 1 to 3 .

\section{CHARACTERISTICS OF $\left[ \pm \theta_{2}\right]_{S}$ OVERAGED LAMINATES}

The series of laminates was fabricated in an identical fashion to the previous set. Briefly, the specimen dimensions were $18 \mathrm{in}$. $(45 \% .2 \mathrm{~mm})$. long by $2 \mathrm{in.}(50.8 \mathrm{~mm})$ wide, the thickness of each ply was $0.005 \mathrm{in} .(0.127 \mathrm{~mm})$, the values for $\theta$ were the same, and the notches were $0.25 \mathrm{in}$. ( $6.35 \mathrm{~mm})$ cen ... tered through the thickness. The laminate configuration was altered to $\left[+\theta_{2}\right]_{s}$ which merely doubled the number of plies and therefore doubled the laminate thickness. This parameter was changed so that the effect of laminate thickness on the fracture characteristics could be investigated.

Elementary analysis would indicate that the fracture loads of the $\left[+\theta_{2}\right]_{S}$ laminates should be double in magnitude to those of the $[+\theta]_{s}$ configuration and should exhibit similar fracture characteristics. However, aside from the laminate thickness, another important factor affecting the fracture is the age of the material, especially since these specimens were fabricated from 3.5 yr old prepreg. Even though experience has shown that this prepreg performs exceptionally well even after its shelf life has been exceeded, it was sus.. pected (based upon limited previous information) that a degradation in strength associated with overaged prepreg would probably occur. Therefore this study was initiated to investigate the strength degradation of an "advanced-cure" prepreg where, in this case, the "advanced-cure" is the result of old or over.. aged prepreg.

The specimens were tested in uniaxial tension by incrementally increasing loads until fracture occurred. The data for the overaged laminates, shown in table II, indicate several trends in the fracture characteristics associated with an overaged prepreg. First of all, since one would expect the fracture loads of the $\left[ \pm \theta_{2}\right]_{s}$ laminates to be about twice those previously recorded for the $[ \pm \theta]_{s}$ laminates, one would then expect to observe approximately the same fracture stresses for each laminate configuration, $[+\theta]_{s}$ and $\left[+\theta_{2}\right]_{5}$. Such is not the case in table II. In fact, with the exception of the unidirectional-notch/hole laminates, all of the overaged laminates experience a degradation in strength when compared to results (refs. 1 to 3 ) shown in table I. The authors believe the experimental fracture loads used to calculate the fracture stresses for both the unidirectional $[0]_{4}$ and $[0]_{8}$ notch/hole laminates do not adequately represent unidirectional composite tensile behavior. Assuming, therefore, that the data points are bad and not to be 
considered in the comparison, then it can be stated that all of the laminates fabricated from the overaged prepreg degraded in tensile strength.

The second trend observed from the data is that as $\theta$ increases, which produces laminates which are matrix/resin dominant, the degradation in strength becomes even more severe. The overaged $\left[ \pm 15_{2}\right]_{5}$. laminates registered only 33 percent (on the average) of the expected fresh prepreg magnitudes while the overaged $\left[ \pm 30_{2}\right]_{S}$ and $\left[ \pm 45_{2}\right]_{S}$ laminates registered 27 percent (on the average). This is an indication that the resin and not the fiber is more sensitive to overaging as expected.

Having observed the severe strength degradation in terms of fracture stress, the fracture surfaces were examined using a scanning electron microscope (SEM) to document microstructural characteristics associated with overaged prepreg. Figure 5 displays the fracture surface and microstructural characteristics for the $[0]_{8}$ laminate. The fracture resulted in splintery pieces. Under magnification these pieces exhibit an irregular morphology. The fibers are broken in bunches at various locations, forming a patchy pattern on the surface. Higher magnifications reveal extensive matrix hackles and debris.

The $\left[ \pm 15_{2}\right]_{s}$ specimens displayed in figure 6 fractured at an angle parallel to a fiber direction. For the notched specimen, the fracture split the specimens into two equal halves. Photomicrographs reveal a flat morphology. Even at lower magnifications, an extensive amount of matrix debris is visible. At higher magnifications, an alternating pattern of rows of fibers and hackles exists. Very few broken fibers were observed. In the presence of a broken fiber, the hackles were larger in size than others in the same view.

Basically, similar fracture characteristics were observed for the $\left[+30_{2}\right]_{s}$ laminate shown in figure 7. Once again the specimen fractured along a line parallel to a fiber direction. For those specimens containing notches, fracture progressed through the center of the machined notches. The morphology of the fracture surface is flat consisting of rows of fibers and hackles. All hackles in a row appear to be the same size; however, the size of the hackles varies from row to row. Very little flber fracture was observed on this surface.

In figure 8 , the characteristics associated with the fracture of the $\left[ \pm 45_{2}\right]_{s}$ laminate are displayed. Again, the specimens fracture in the same manner previously observed. The angle of fracture coincides with the $45^{\circ}$ orientation of the fibers. The fracture surface is flat and littered with matrix debris. The fibers and hackles alternate in rows where the sizes of the hackles are varied throughout each row.

The fracture characteristics for the angleplied $\left[ \pm \theta_{2}\right]_{s}$ laminates fabricated from the overaged prepreg are similar regardless of the ply configuration. Since this laminate-independency was not observed before, it is believed that this behavior is due to the material itself. Characteristics such as the extensive amount of matrix debris along with the numerous hackles are indicative of matrix shear fracture. The clean exposed fibers show that debonding has occurred from the resin. The lack of fiber fracture indicates that the loads being applied prior to fracture were relatively low. These characteristics described above will accompany an overaged/"advanced-cure" prepreg. Since the prepreg is decomposing chemically, the ability to transfer sufficient shear stress through the composite laminate is diminishing. 


\section{FRACTURE CHARACTERISTICS OF $\left[\mathrm{I}_{2}\right]_{S}$ FRESH LAMINATES}

In documenting the characteristics associated with overaged prepreg, comparison of $\left[ \pm \theta_{2}\right]_{s}$ characteristics was made to a series of $[+\theta]_{s}$ laminates which was fabricated from a controlled fresh batch of graphite/epoxy prepreg. As previously mentioned, the age of the material wa's not the only distinguishable difference, since one set of laminates was twice as thick as the other.

To determine if the laminate thickness as well as the age of the prepreg contributed to the results presented thus far, a new batch of graphite/epoxy prepreg was purchased. From this fresh batch, five unnotched replicates of each laminate configuration, $[0]_{8},\left[ \pm 15_{2}\right]_{s},\left[+30_{2}\right]_{5}$, and $\left[ \pm 45_{2}\right]_{s}$ were fabricated and tested in uniaxial tension to fracture.

The experimental data (fracture loads), which displayed repeatability, were used to formulate the fracture stresses for the fresh prepreg $\left[+\theta_{2}\right]_{5}$ laminates in table III. The thickness effect alone would indicate that the fracture loads of the $\left[ \pm \theta_{2}\right]_{s}$ laminates should be double in magnitude to those observed for the $[+\theta] s$ laminates. If this were the case, then the fracture stresses (which were calculated from the experimental fracture loads) displayed in tables $I$ and $I I I$ for the $[ \pm \theta]_{S}$ and $\left[ \pm \theta_{2}\right]_{S}$ laminates., respectively; should be of the same magnitude. Comparing the fracture stresses for the unnotched specimens in table I to the average fracture stresses in table III, it is revealed that the fracture loads for these thicker laminates exceeded the predictions, exhibiting exceptional tensile strength, thereby eliminating laminate thickness as a significant factor in the degradation of strength.

Finally, the physical fracture characteristics of these specimens shown in figure 9 resemble those previously photogrpahed for the $[ \pm \theta]_{S}$ laminates. Primarily, the specimens are breaking at two different locations producing jagged, irregular surfaces.

\section{COMPARISONS AND DISCUSSION}

In comparing the data and results of the $[+\theta]_{s}$ graphite/epoxy laminates to those of the $\left[\mathrm{t}_{2}\right]_{\mathrm{s}}$ overaged graphite/epoxy laminates, it was shown that the overaged Taminates do degrade in strength substantially and they produce unique microstructural characteristics.

In summarizing the characteristics of the $[+\theta]_{s}$ laminates, photo: micrographs reveal distinct microstructural characteristics for each angleplied laminate fracture surface examined. This indicates that the fracture characteristics are a function of the ply angle orientation. The fracture of the specimen itself usually occurred in two places producing a jagged, irregular surface.

The unidirectional laminate $\left([0]_{8}\right)$ did exhibit some degradation in strength; however it was slight in comparison to that of the angleplied laminates. As previously mentioned, the resin is found to be more sensitive to overaging. Since the unidirectional laminate is fiber dominant, the degradation was expected to be minimal. This is manifested in comparing the photomicrographs of the two laminates. One would expect the microstructural characteristics of the $[0]_{8}$ laminate in figure 5 to be very similar in 
nature to those of the $[0]_{4}$ laminate in figure 1 since both laminates are fiber dominant. The unidirectional laminate made from the overaged prepreg does possess the fiber breakage and tiered pattern which was documented for the $[0]_{4}$ laminate. However, the alternating fiber/hackle pattern is also present in the patchy areas of the surface which, in this paper is shown to be associated with an overaged prepreg.

The angleplied overaged $\left[\mathrm{t}_{2}\right]_{S}$ laminates fractured along a plane that was parallel to a fiber direction, producing very smooth and flat surfaces. The fracture loads were substantially lower for these laminate con. figurations. The microstructural characteristics of the angleplied fracture surfaces were not distinct. Each revealed extensive matrix debris along with hackles of various sizes. The hackles surrounding the fibers in the photomicrographs establish a pattern which consists of alternating rows of fibers and hackles. Since these characteristics were observed on all the surfaces regardless of ply angle orientation, it is presumed that these microstructural characteristics are the product of an overaged prepreg.

One other point worth mentioning is that the physical handing of these fractured $\left[ \pm \theta_{2}\right]_{S}$ overaged laminates resulted in a black greasy residue on the skin. The authors have never observed this before even though hundreds of graphite/epoxy specimens have been handled. This is apparently indicative of a chemical breakdown of the old resin and is an additional characteristic of an overaged prepreg.

The fracture loads, surface features, and microstructural characteristics observed and recorded for this particular series of specimens is unique to this batch based upon comparisons made with results from similar studies. Therefore, it is concluded that the overaged graphite/epoxy prepreg does degrade in strength, fractures in a brittle fashion, possesses unique microstructural characteristics, and for this particular prepreg, attains this state at an age of approximately $2.5 \mathrm{yr}$. This is based on results previously obtained wherein the strengths had not deteriorated significantly for specimens fabricated for 2 yr old prepreg.

These conclusions have been substantiated by an analytical investigation which was conducted in conjunction with the experimental investigation. The ICAN (Integrated Composites Analyzer) computer code (ref. 6) was used to model and analyze the eight ply $\left(\left[+\theta_{2}\right]_{5}\right)$ laminates. Results from the analysis which include laminate fracture stress predictions as a function of intralaminar shear stress are shown in figure 10 for the $\left[ \pm 15_{2}\right]_{s}$ laminate and in figure 11 for the $\left[ \pm 30_{2}\right]_{s}$ and $\left[ \pm 45_{2}\right]_{s}$ laminates.

The fracture stress is plotted as a function of the perturbed intralaminar shear strength. The intralaminar shear strength was perturbed in order to determine the intralaminar strength at which the laminate fractured. The ICAN code has the capability of predicting the fracture stress not only for room temperature/dry conditions but also accounting for residual stresses resulting from the $350{ }^{\circ} \mathrm{F}$ cure temperature of the prepreg. Both are included on the graphs. The solid line depicts ICAN results when residual stresses are taken into account and the dashed line depicts room temperature/dry conditions with. out residual stresses. The experimental fracture loads for each series of laminates are used to calculate the fracture stresses which are depicted symbolically. In figures 10 and 11 , a triangle corresponds to the overaged laminates, a circle for the $[ \pm \theta]_{s}$ laminate data which was used for the 
comparison and a square represents the laminates which were fabricated from the fresh prepreg. The various data symbols were placed on the analytical curves at the point corresponding to the experimentally determined fracture stresses (the ordinate). Due to the scale selection, only the $\left[ \pm 75_{2}\right]_{s}$ plots include the experimental data for the fresh prepreg. The superior tensile strengths of the $\left[ \pm 30_{2}\right]_{S}$ and $\left[ \pm 45_{2}\right]_{S}$ fresh prepreg laminates (table III) exceed the limits selected for the scale representing this data in figure 11 and therefore are not shown.

The analytical results in figures 10 and 11 show that for the actual fracture stresses the corresponding intralaminar shear stresses associated with the overaged laminates are lower than the thinner $[+\theta]_{s}$ laminates and substantially lower than those made with fresh prepreg. As expected, the degrada tion in shear strength is more severe for the $\left[ \pm 30_{2}\right]_{s}$ and $\left[ \pm 45_{2}\right]_{s}$ laminates. The only factor separating the data points is the age of the prepreg. Since the intralaminar shear strength is a property of the resin primarily. the analytical results indicate that the degradation in shear strength is the result of a deteriorating resin which is caused by overaging.

Results from the ICAN program did indeed corroborate those resulting from the experimental investigation, namely that the overaging results in a weakening of the resin which fractures in shear at a reduced load producing unique characteristics on the fracture surface associated with the overaged resin.

\section{SUMMARY OF RESULTS}

Laminates fabricated from the overaged prepreg as expected experience a degradation in strength. This type of prepreg also produces unique microstructural characteristics on the fracture surface. For this case discussed, the "advanced-cure" was the result of overaging. However, "advanced-cure" can also occur. in a fresh prepreg when exposed to the environmental conditions of moisture and temperature for some extended period. Note that neither of these conditions needs to be severe to serve as a catalyst for "advanced-cure" lead. ing to degradation. In fact, this phenomenon can occur when a prepreg is exposed to room temperature and normal humidity. The results presented herein provide the experimentalist/analyst with another source of data to consider in a post-failure investigation, especially when anomalies in failure characteristics exist.

\section{REFERENCES}

1. Irvine, T.B.; and Ginty, C.A.: Progressive Fracture of Fiber Composites. NASA TM-83701, 1983.

2. Ginty, C.A.; and Irvine, T.B.: Fracture Surface Characteristics of Notched Angleplied Graphite/Epoxy Composites. NASA TM-83786; 1984.

3. Irvine, T.B.; and Ginty, C.A.: Fracture Modes in Notched Angleplied Composite Laminates. NASA TM-83802, 1984.

4. Clements, L.L.: Deformation and Fallure Mechanisms of Graphite/Epoxy Composites Under Static Loading. (FR-22-3, Advanced Research and Applications Corp.; NASA Contract NAS 2-9989) NASA CR-166328, 1.981. 
5. Clements, L.L.; and Adamson, M.J.: Failure of Morphology of $\left(0^{\circ}\right)_{8}$ Graphite/Epoxy as Influenced by Environments and Processing. NASA TM-81318, 1981 .

6. Murthy, P.L.N.; and Chamis, C.C.: ICAN: Integrated Composites Analyzer. AlAA Paper 84-0974, May 1984.

TABLE I. - FRACTURE STRESSES OF THE GRAPHITE/EPOXY $[ \pm \theta]_{S}$ LAMINATLS

\begin{tabular}{|l|l|c|c|c|c|c|c|c|}
\hline \multirow{2}{*}{$\begin{array}{c}\text { Specimen } \\
\text { type }\end{array}$} & \multicolumn{4}{|c|}{$\begin{array}{c}\text { Fracture stress, } \\
\text { ksi }\end{array}$} & \multicolumn{4}{c|}{$\begin{array}{c}\text { Fracture stress, } \\
\text { N/mm }\end{array}$} \\
\cline { 2 - 9 } & {$[0]_{4}$} & $[ \pm] 5]_{S}$ & {$[ \pm 30]_{S}$} & {$[+45]_{S}$} & {$[0]_{4}$} & {$[ \pm 15]_{S}$} & {$[ \pm 30]_{S}$} & {$[ \pm 45]_{S}$} \\
\hline Unnotched & 202 & 93 & 66 & 23 & 1393 & 641 & 455 & 159 \\
Notch/s 1it & 195 & 72 & 54 & 22 & 1344 & 496 & 372 & 152 \\
Notch/hole & 150 & 83 & 44 & 24 & 1034 & 512 & 303 & 165 \\
\hline
\end{tabular}

TABIE II. - FRACTURE STRESSES OF THE OVERAGED GRAPHITE/EPOXY $\left[ \pm \theta_{2}\right]_{S}$ LAMINATES

\begin{tabular}{|l|c|c|c|c|c|c|c|c|}
\hline \multirow{2}{*}{$\begin{array}{c}\text { Specimen } \\
\text { type }\end{array}$} & \multicolumn{4}{|c|}{$\begin{array}{c}\text { Fracture stress, } \\
\text { ksi }\end{array}$} & \multicolumn{4}{|c|}{$\begin{array}{c}\text { Fracture stress, } \\
\mathrm{N} / \mathrm{mm}^{2}\end{array}$} \\
\cline { 2 - 9 } & {$[0]_{8}$} & {$\left[ \pm 15_{2}\right]_{\mathrm{S}}$} & {$\left[ \pm 30_{2}\right]_{\mathrm{S}}$} & {$\left[ \pm 45_{2}\right]_{\mathrm{S}}$} & {$[0]_{8}$} & {$\left[ \pm 15_{2}\right]_{\mathrm{S}}$} & {$\left[ \pm 30_{2}\right]_{\mathrm{S}}$} & {$\left[ \pm 45_{2}\right]_{\mathrm{S}}$} \\
\hline Unnotched & 163 & 43 & 20 & - & 1124 & 296 & 138 & $\ldots$ \\
Notch/s1it & 169 & 25 & 15 & 6 & 1165 & 172 & 103 & 41 \\
Notch/hole & 198 & 14 & 9 & 6 & 1365 & 97 & 62 & 41 \\
\hline
\end{tabular}

TABI_E III. - FRACTURE STRESSES OF THE FRESH GRAPHITE/EPOXY $\left[ \pm \theta_{2}\right]_{S}$ LAMINATES

\begin{tabular}{|c|c|c|c|c|c|c|c|c|}
\hline \multirow{2}{*}{ Replicate } & \multicolumn{4}{|c|}{$\begin{array}{c}\text { Fracture stress, } \\
\text { ksi }\end{array}$} & \multicolumn{4}{c|}{$\begin{array}{c}\text { Fracture stress, } \\
N / \mathrm{mm}^{2}\end{array}$} \\
\cline { 2 - 8 } & {$[0]_{8}$} & {$\left[ \pm 5_{2}\right]_{\mathrm{S}}$} & {$\left[ \pm 30_{2}\right]_{\mathrm{S}}$} & {$\left[ \pm 45_{2}\right]_{\mathrm{S}}$} & {$[0]_{8}$} & {$\left[ \pm 5_{2}\right]_{\mathrm{S}}$} & {$\left[ \pm 30_{2}\right]_{\mathrm{S}}$} & {$\left[ \pm 45_{2}\right]_{\mathrm{S}}$} \\
\hline 1 & 210 & 140 & 75 & 30 & 1448 & 965 & 517 & 207 \\
2 & 261 & 143 & 75 & 31 & 1799 & 986 & 517 & 214 \\
3 & 206 & 144 & 74 & 29 & 1420 & 993 & 510 & 200 \\
4 & 254 & 128 & 75 & 29 & 1751 & 882 & 517 & 200 \\
5 & $\cdots$ & 125 & 75 & 30 & $\cdots \cdots$ & 862 & 517 & 207 \\
\hline
\end{tabular}


ORIGINAL PROF IS

CE POOR QUALITY
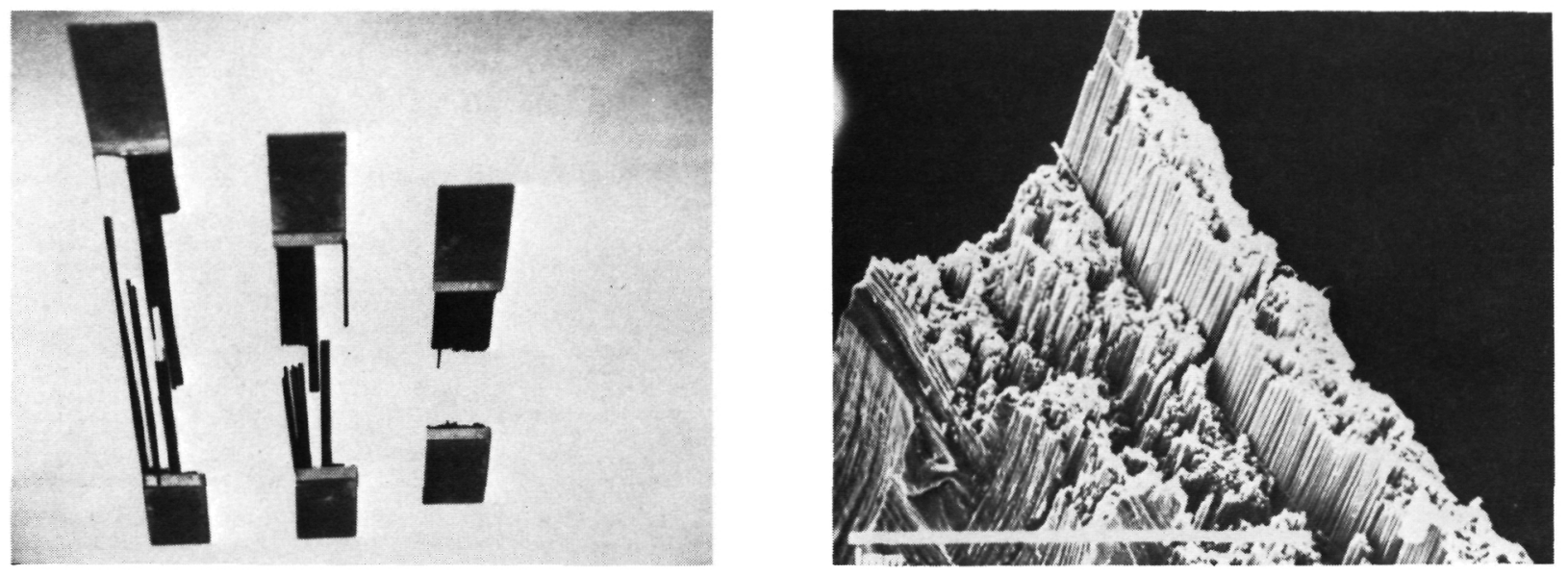

$71 X$

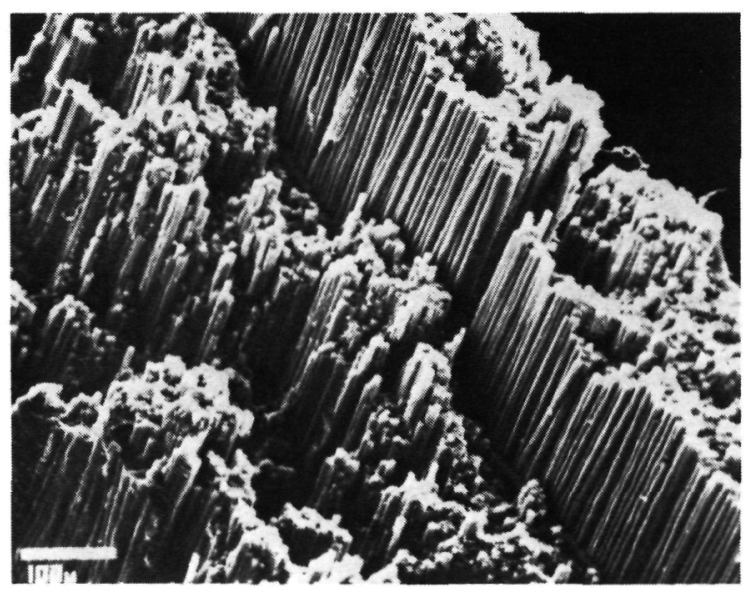

$280 X$

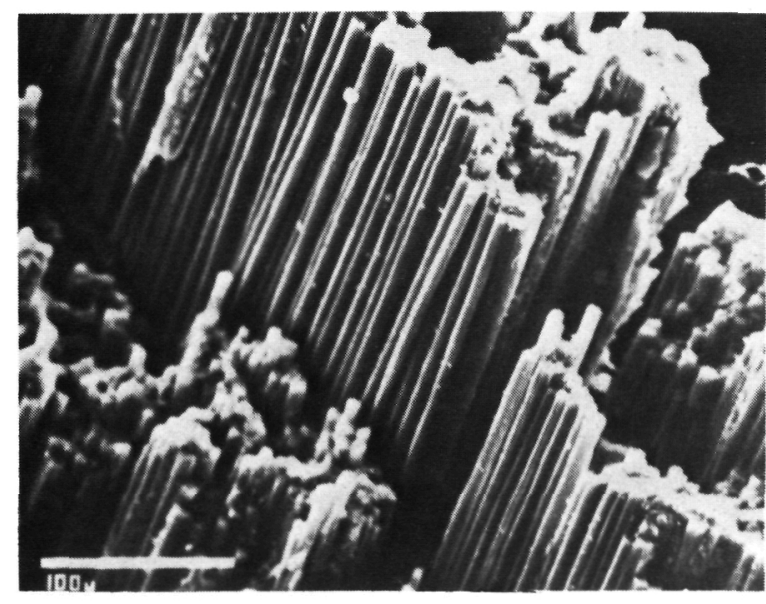

$150 X$

Figure 1. - The fractured specimens and typical microstructural characteristics for the $[0]_{4}$ laminate. 

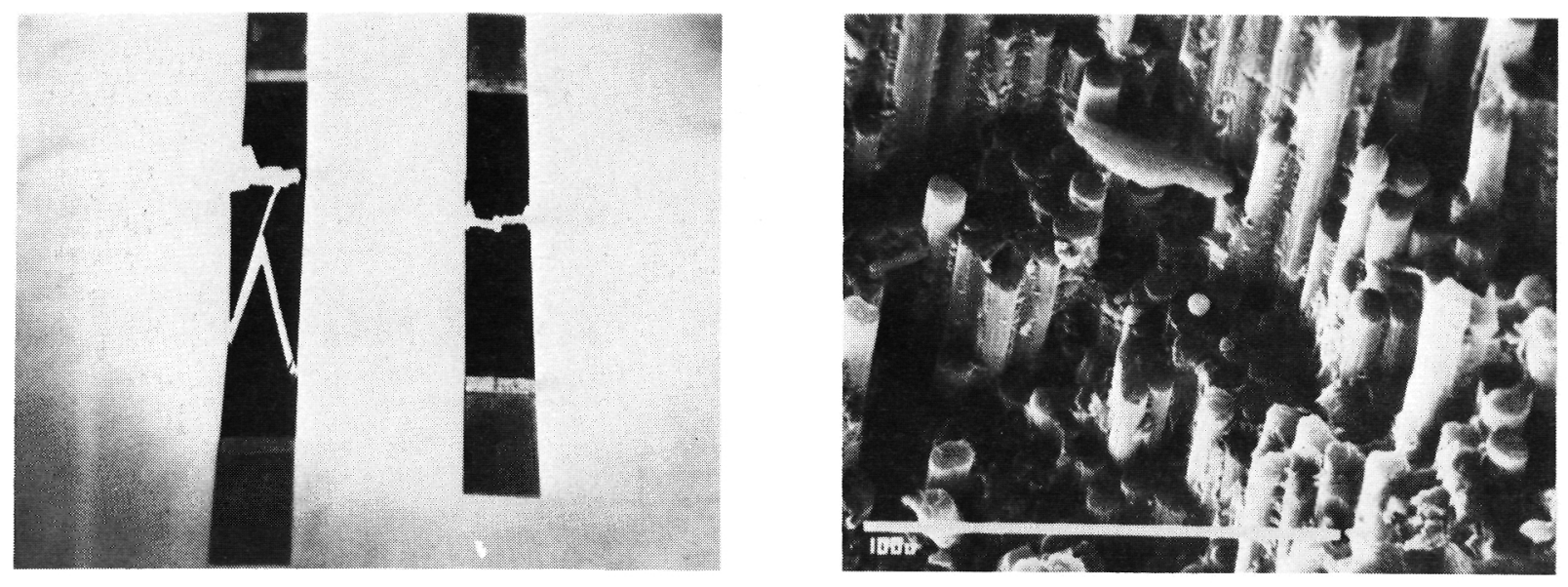

'730X

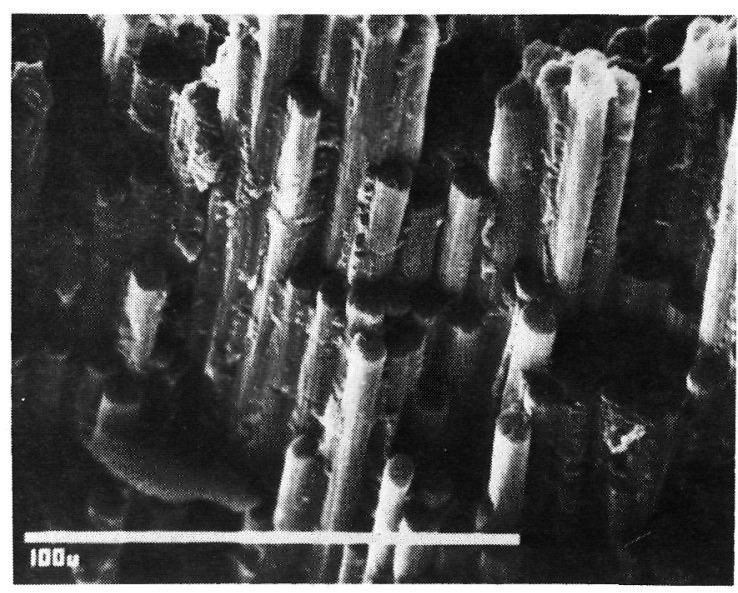

730X

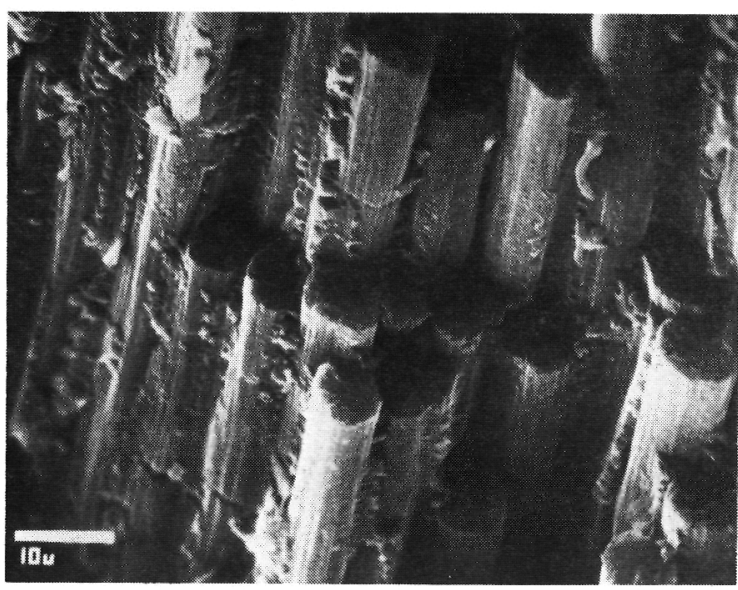

1500X

Figure 2. - The fractured specimens and typical microstructural characteristics for the $[+15]_{\mathrm{S}}$ laminate. 
ORIGIUAL PECE IS

OF POOR QUALITY
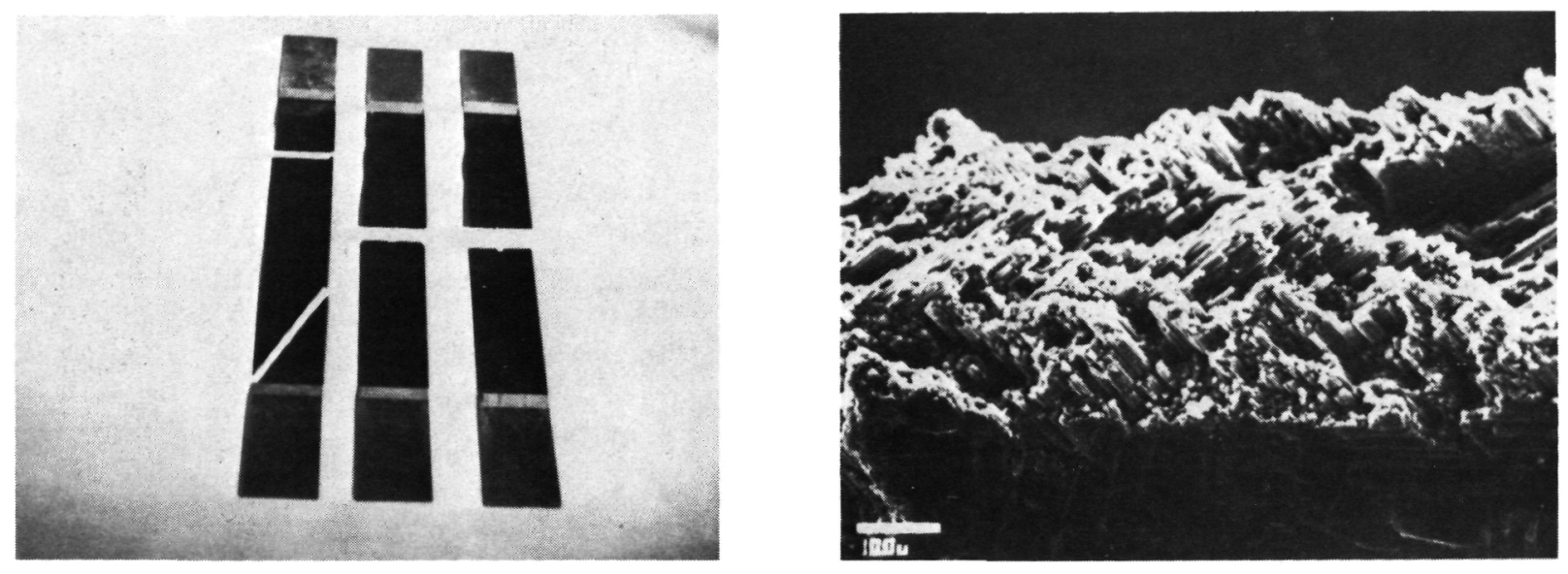

$130 X$

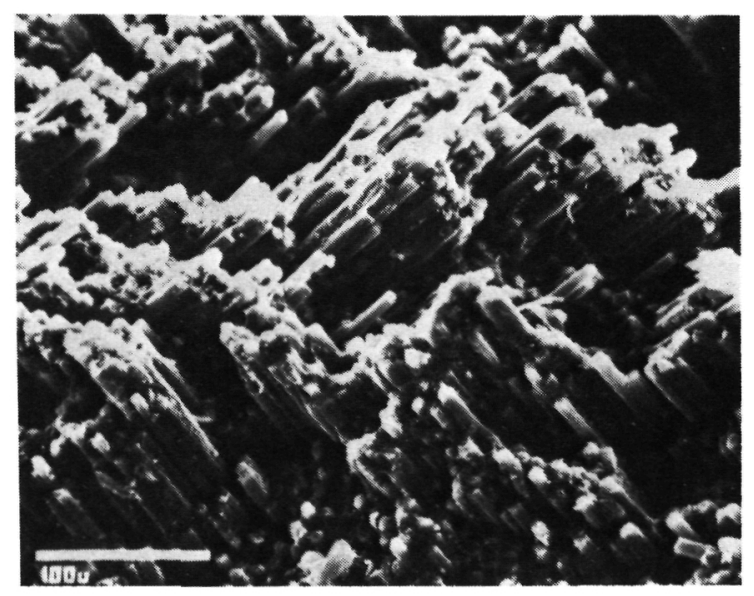

$260 x$

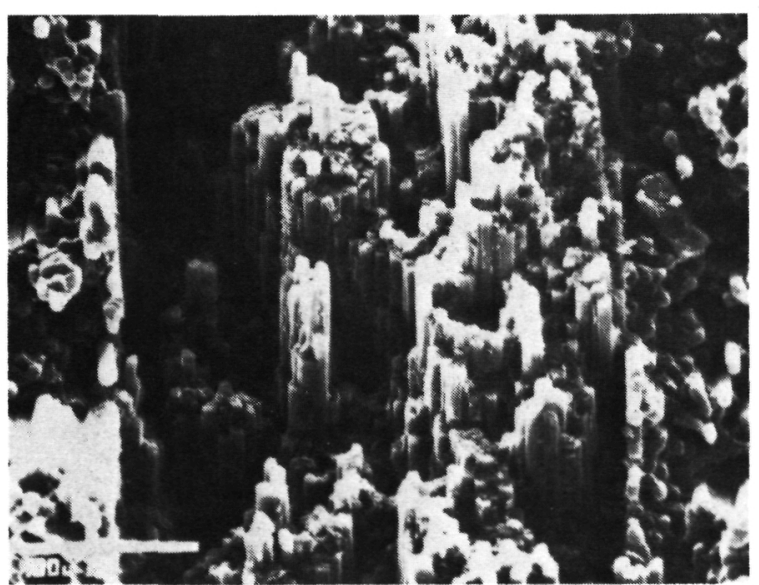

$290 X$

Figure 3. - The fractured specimens and typical microstructural characteristics for the $[ \pm 30]_{\mathrm{S}}$ laminate. 

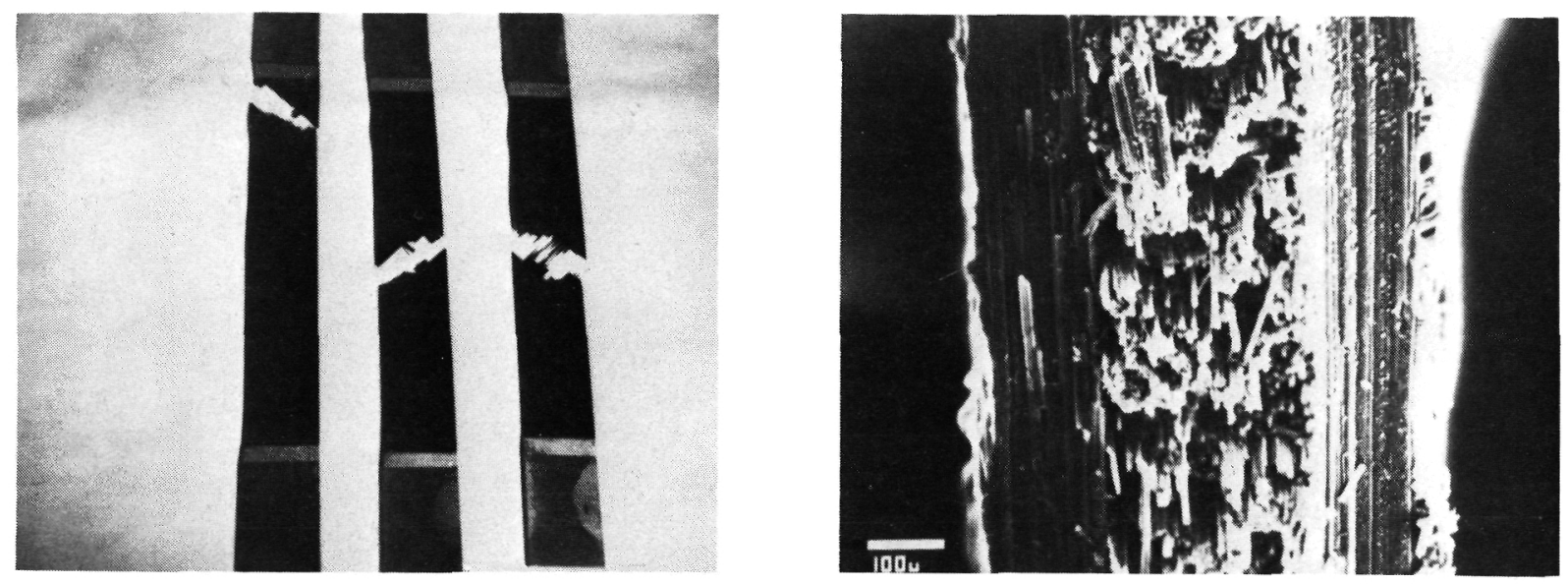

$120 \mathrm{X}$

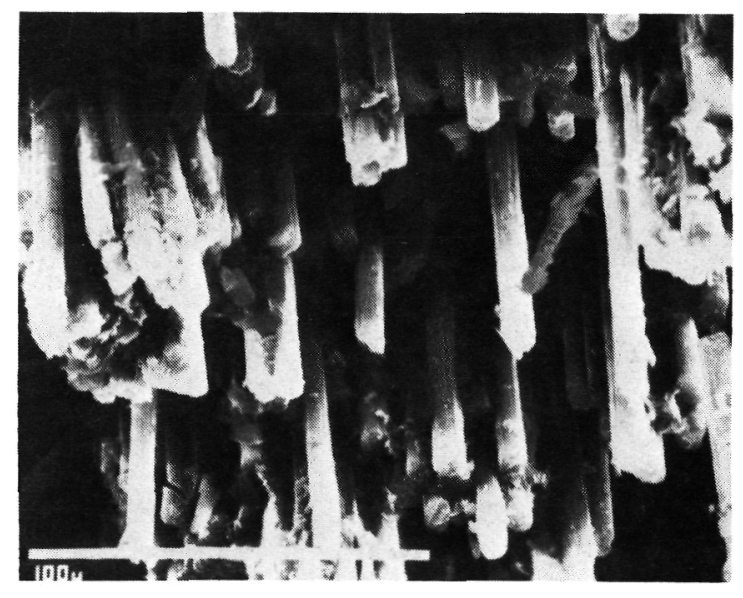

$600 x$

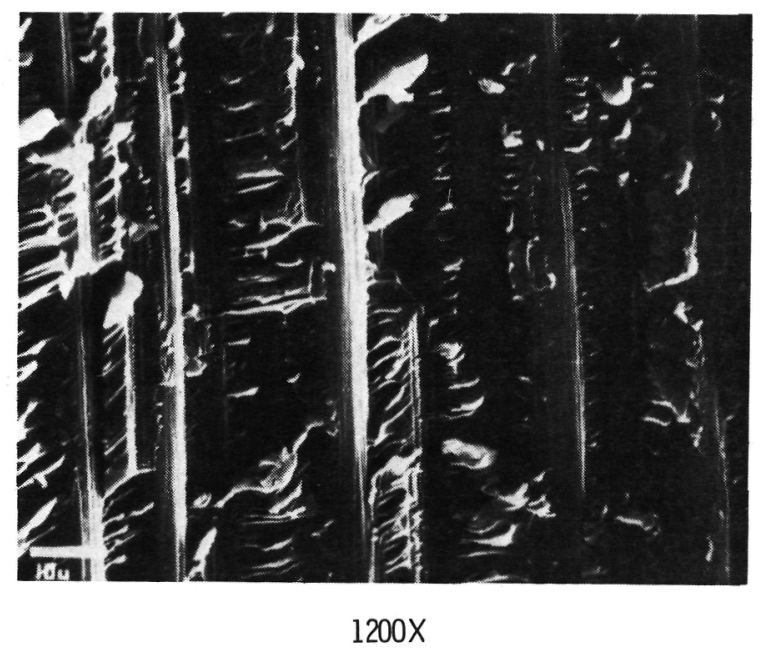

Figure 4. - The fractured specimens and typical microstructural characteristics for the $[+45]_{S}$ laminate. 


\section{ORIGHAL PECE Is \\ OF. POOR QUALITY}
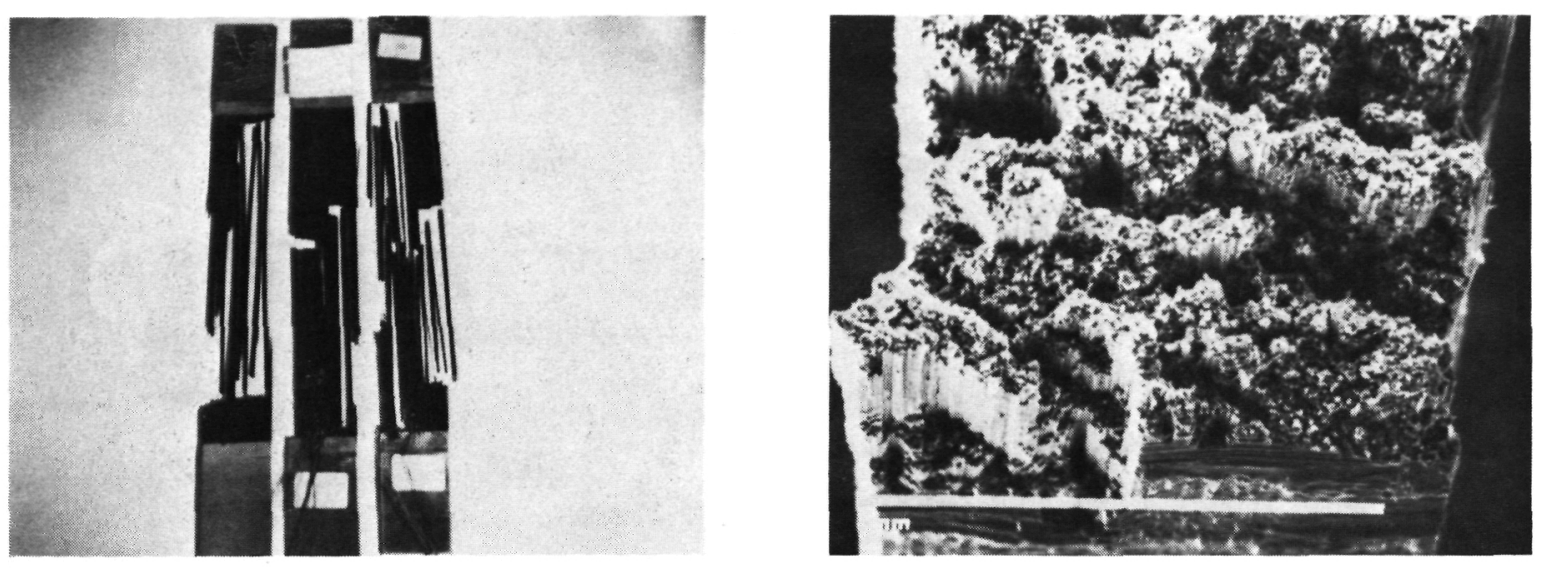

$81 X$

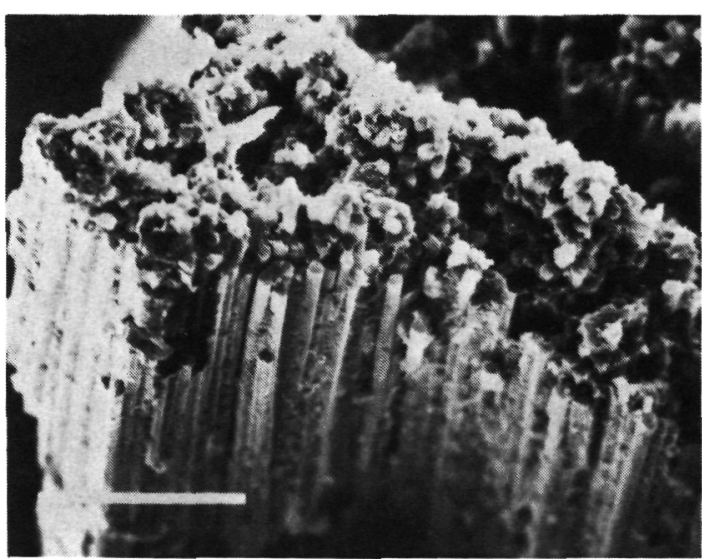

$320 x$

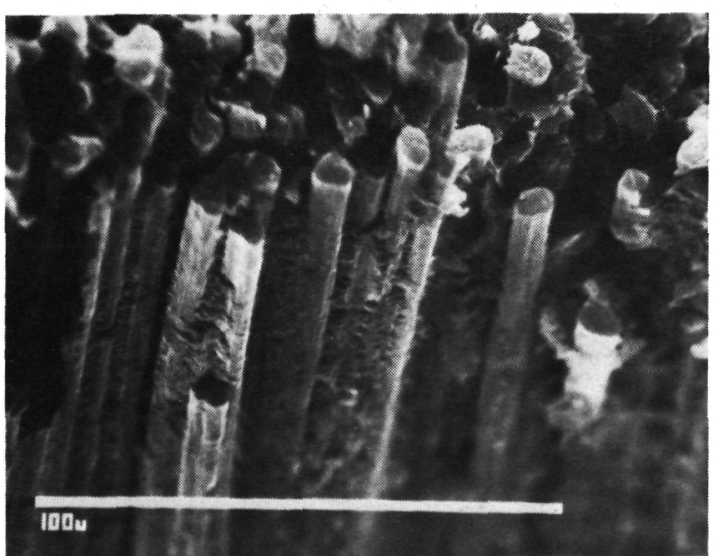

$820 x$

Figure 5. - Fracture characteristics associated with an overaged $[0]_{8}$ laminate. 

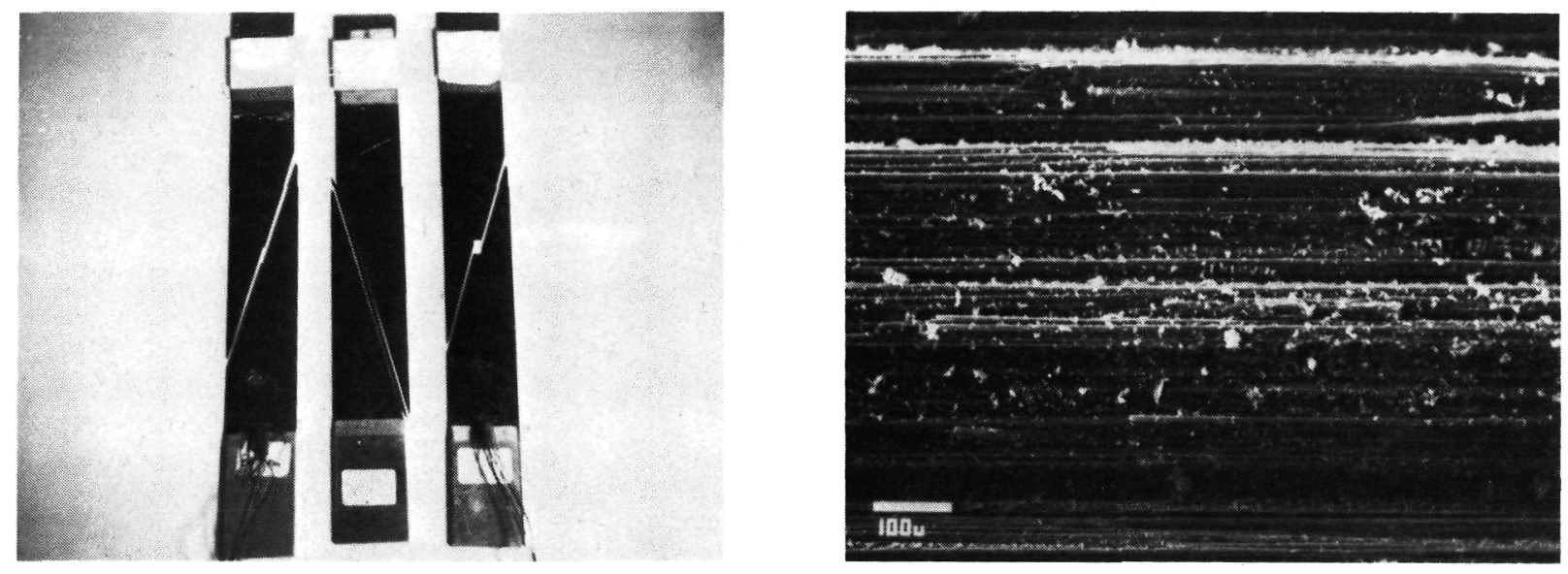

$290 X$

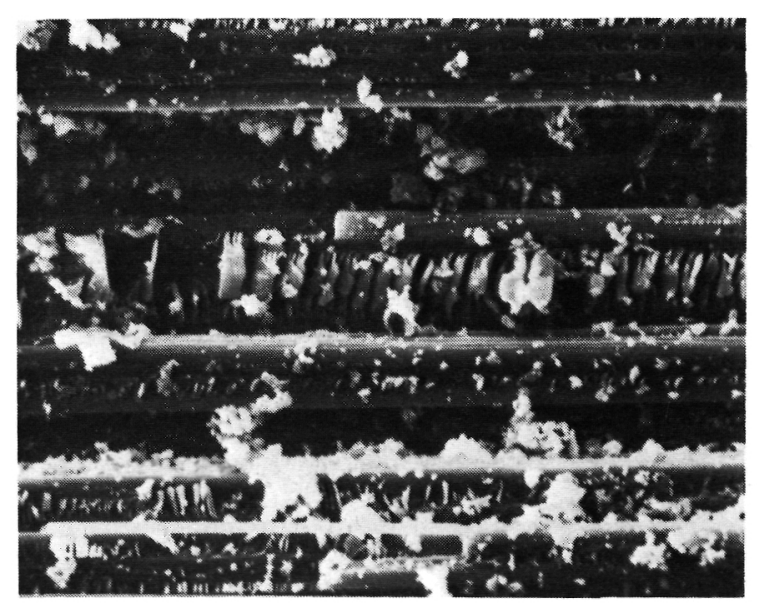

$620 x$

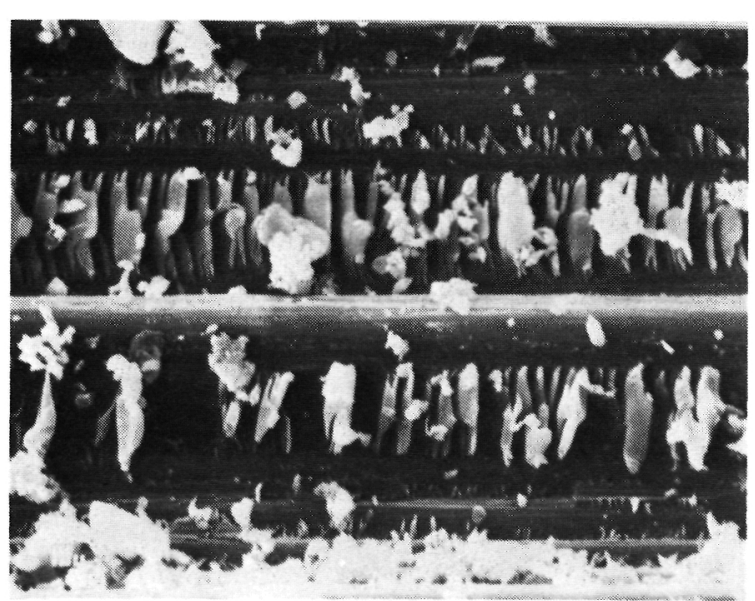

$1200 X$

Figure 6. - Fracture characteristics as sociated with an overaged $\left[ \pm 15_{2}\right]_{\mathrm{S}}$ laminate. 
ORIGINAL PAGE IS

OE POOR QUALITY
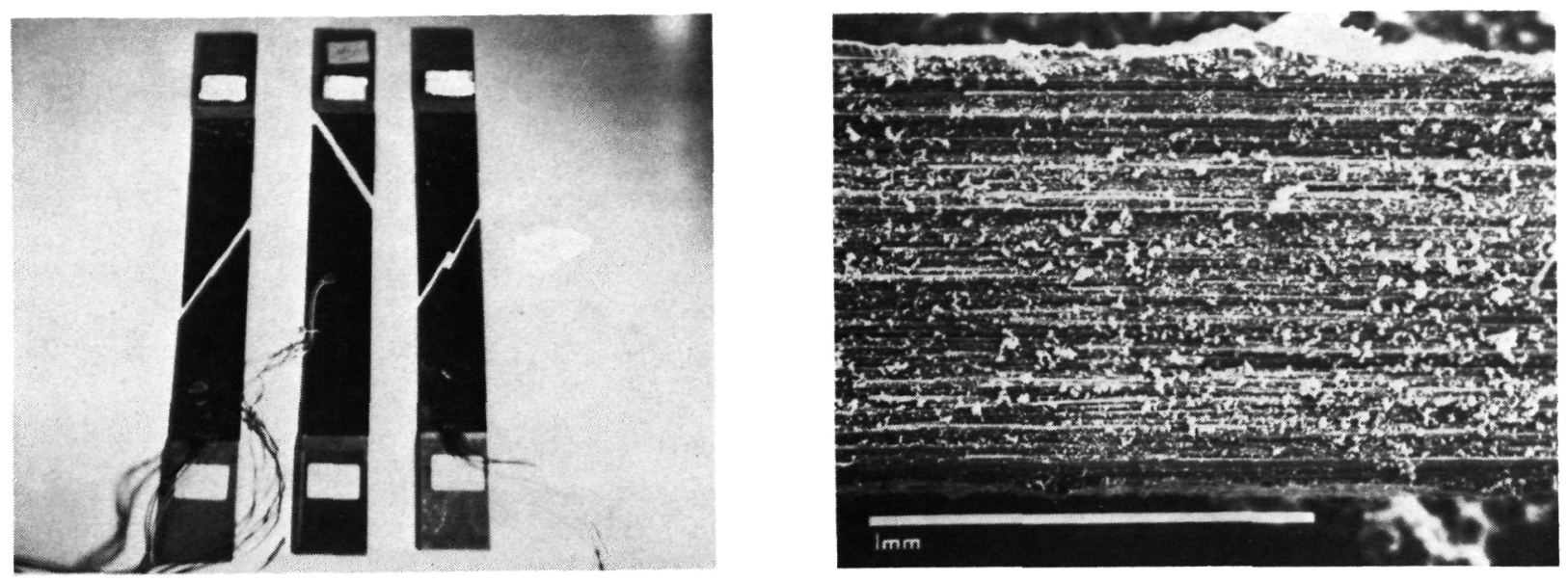

$68 x$
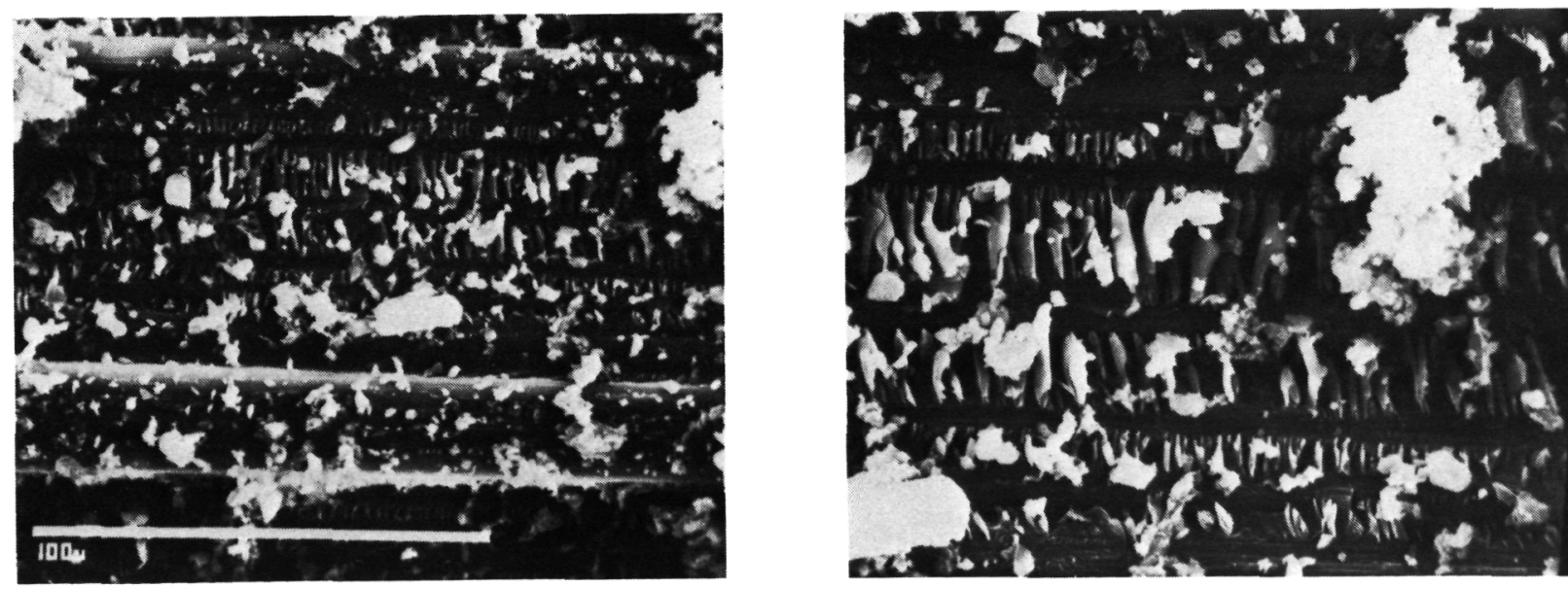

$690 x$

$1400 X$

Figure 7. - Fracture characteristics associated with an overaged $\left[+30_{2}\right]_{\mathrm{S}}$ laminate. 

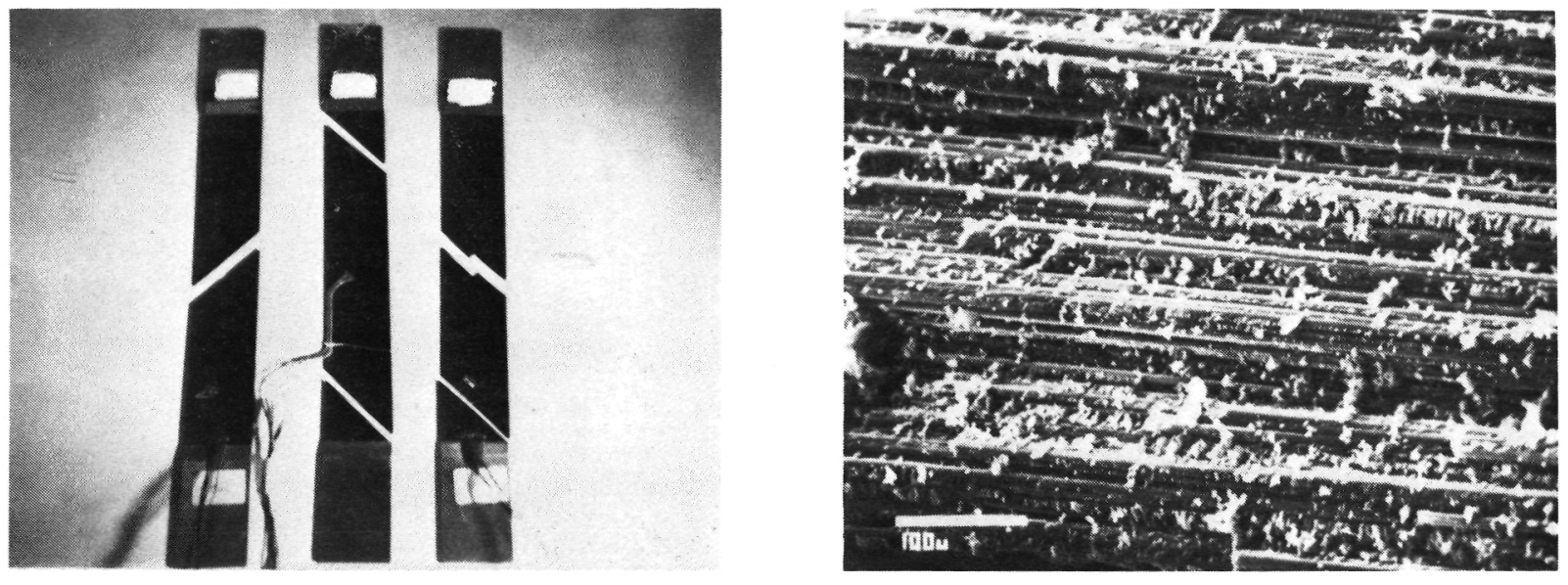

$200 x$

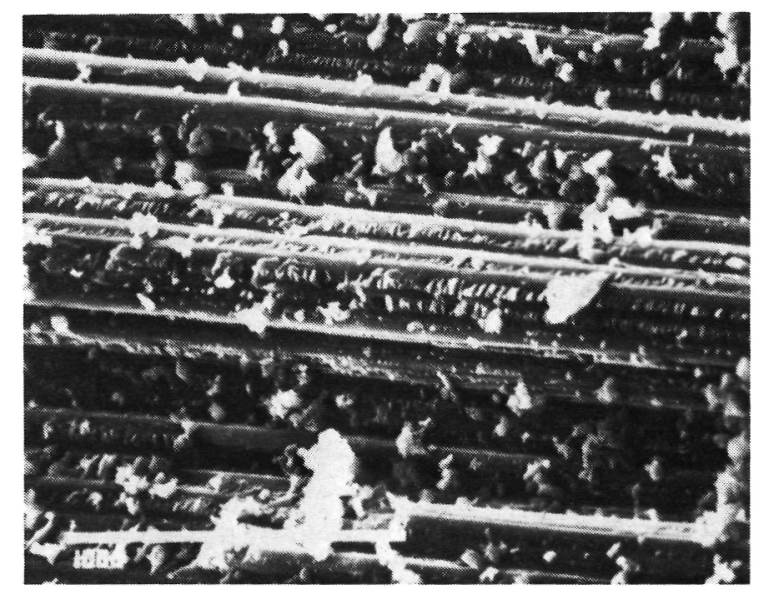

$500 x$

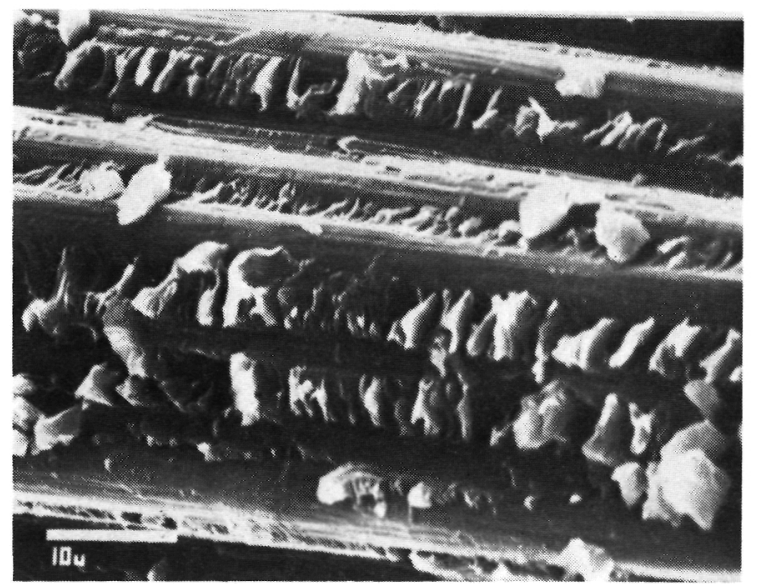

$2000 X$

Figure 8. - Fracture characteristics associated with an overaged $\left[ \pm 45_{2}\right]_{\mathrm{S}}$ laminate. 
PRIGINAL PAGE IS

DE POOR OUALITY

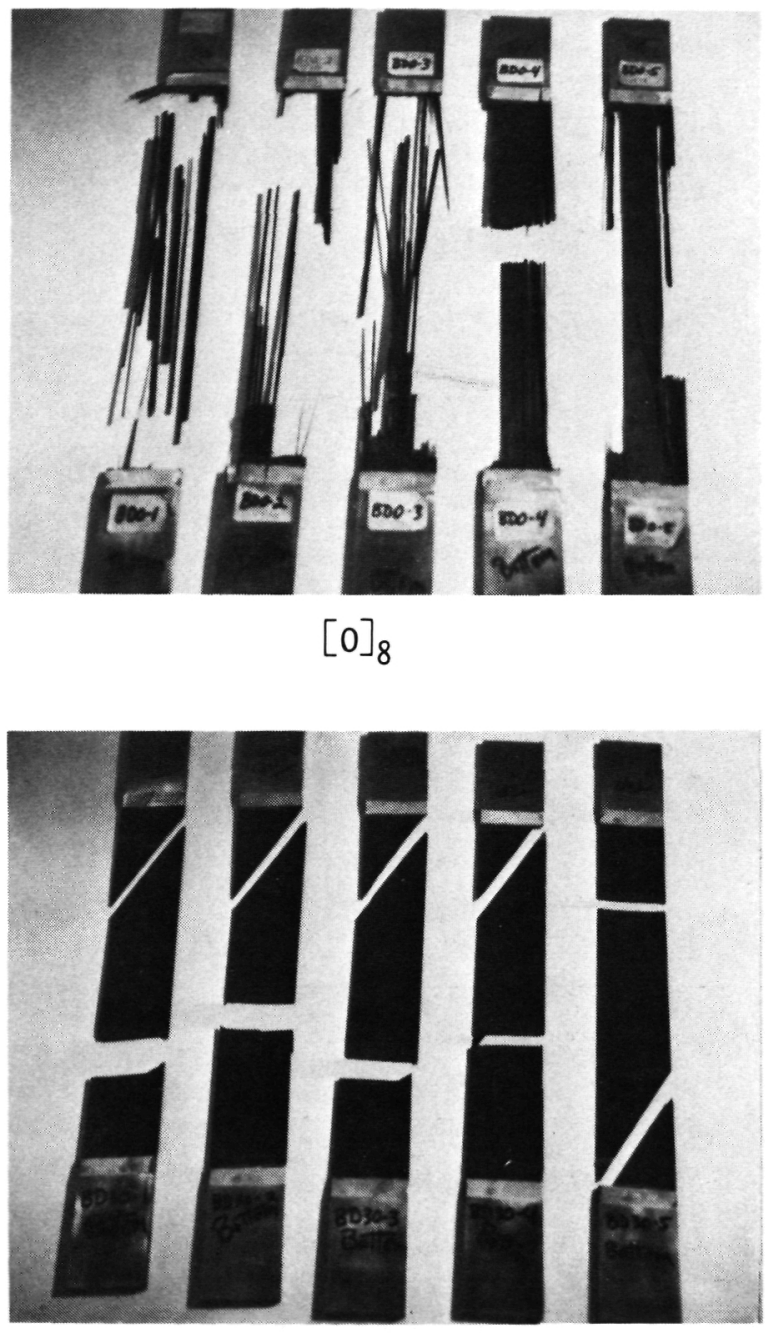

$\left[ \pm 30_{2}\right]_{\mathrm{S}}$

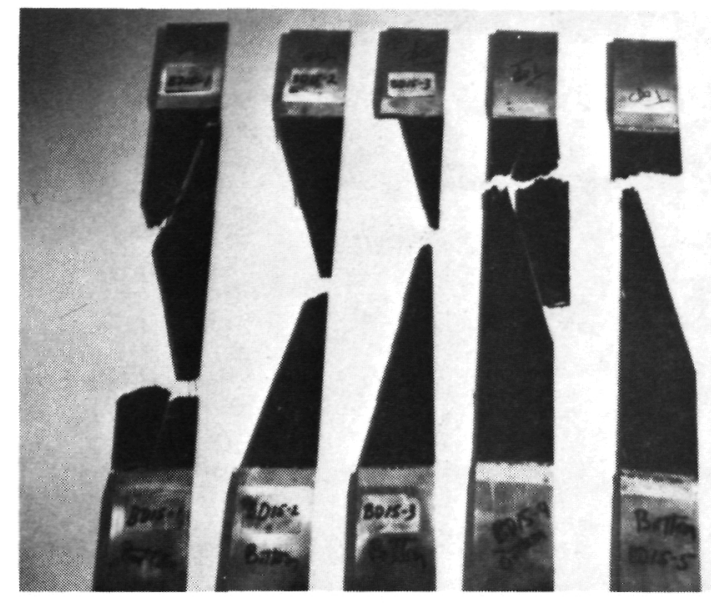

$\left[ \pm 15_{2}\right]_{\mathrm{s}}$

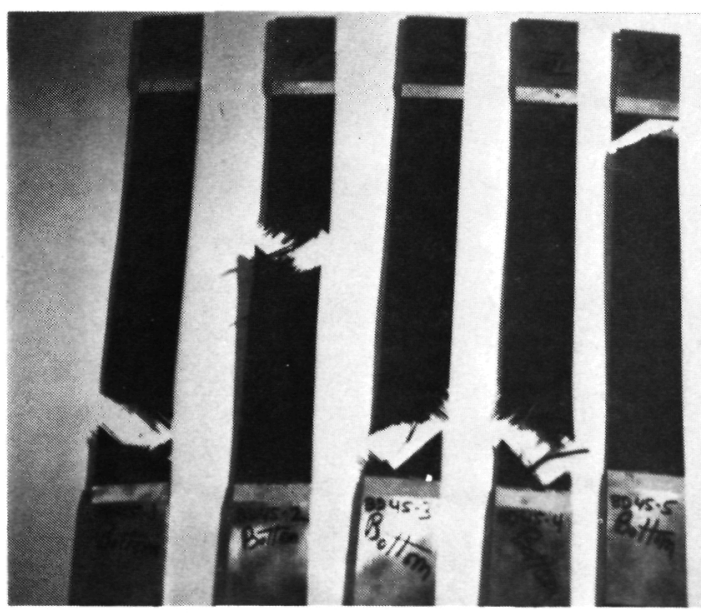

$\left[ \pm 45_{2}\right]_{\mathrm{s}}$

Figure 9. - Fractured graphite/epoxy specimens fabricated from a fresh batch of prepreg. 


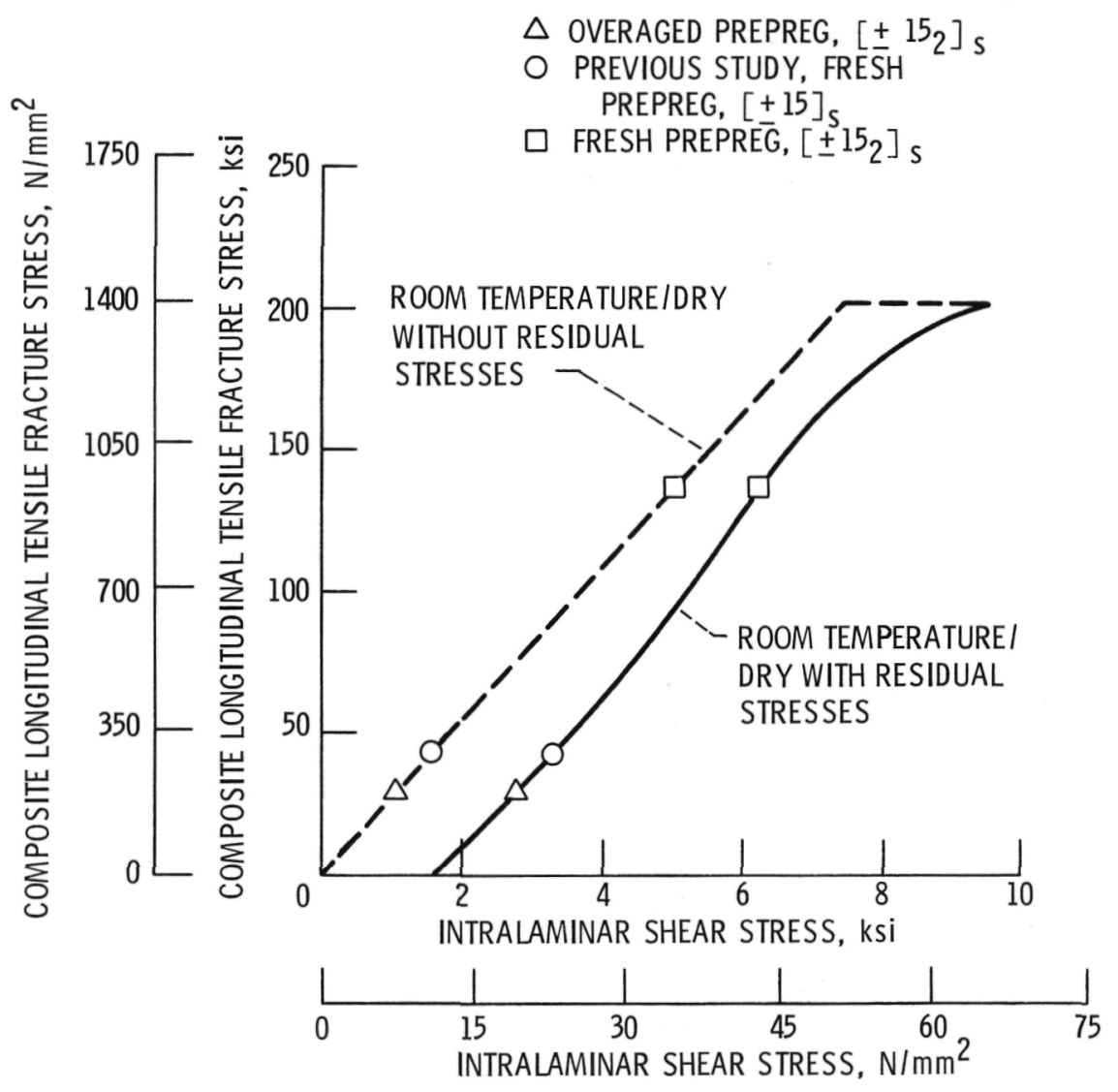

Figure 10. - Composite fracture stresses as a function of intralaminar shear stress for the laminates where $\theta=15^{\circ}$. 


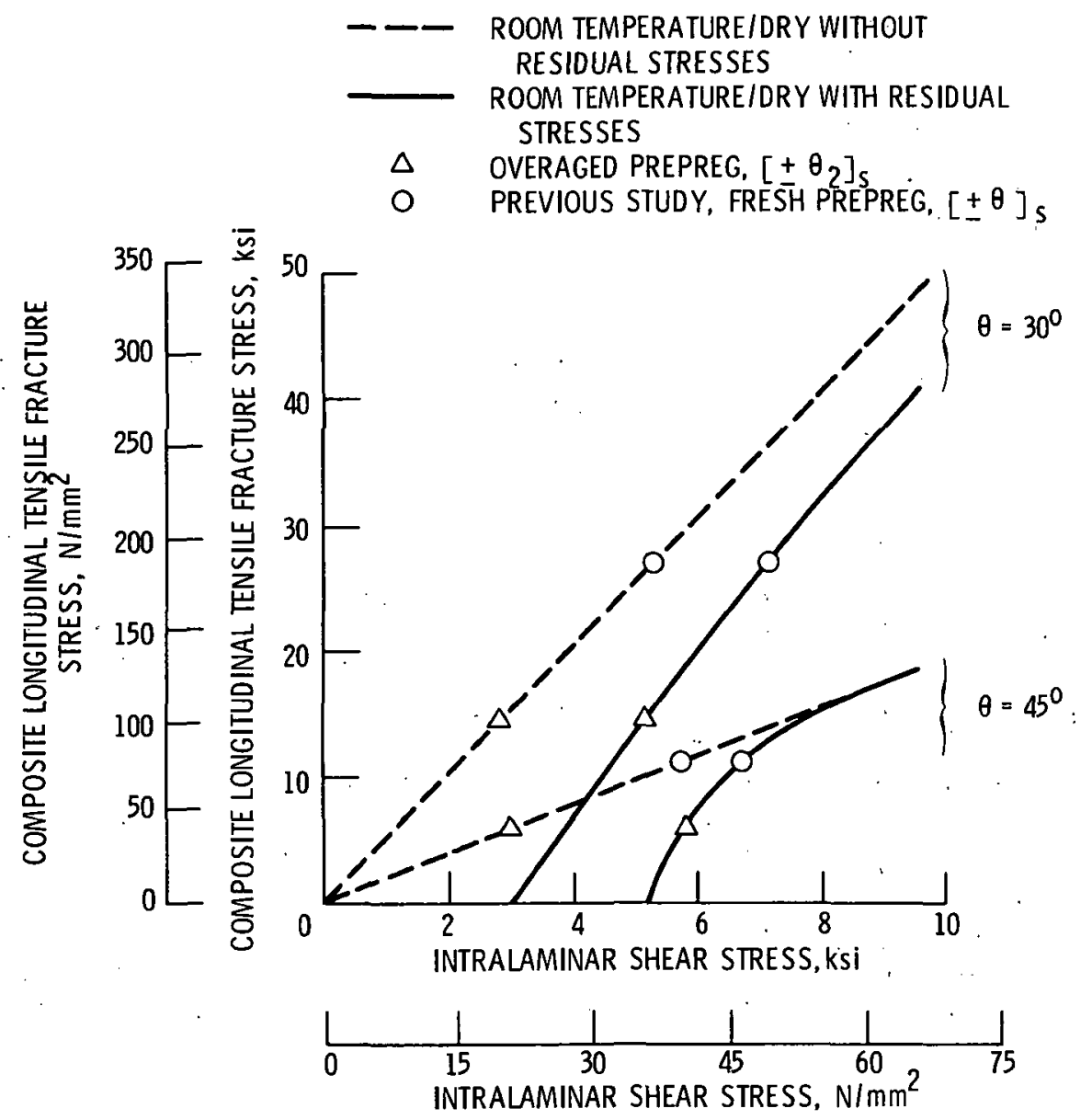

Figure 11. - Composite fracture stresses as a function of intralaminar shear stress for the laminates where $\theta=30^{\circ}$ and $45^{\circ}$. 


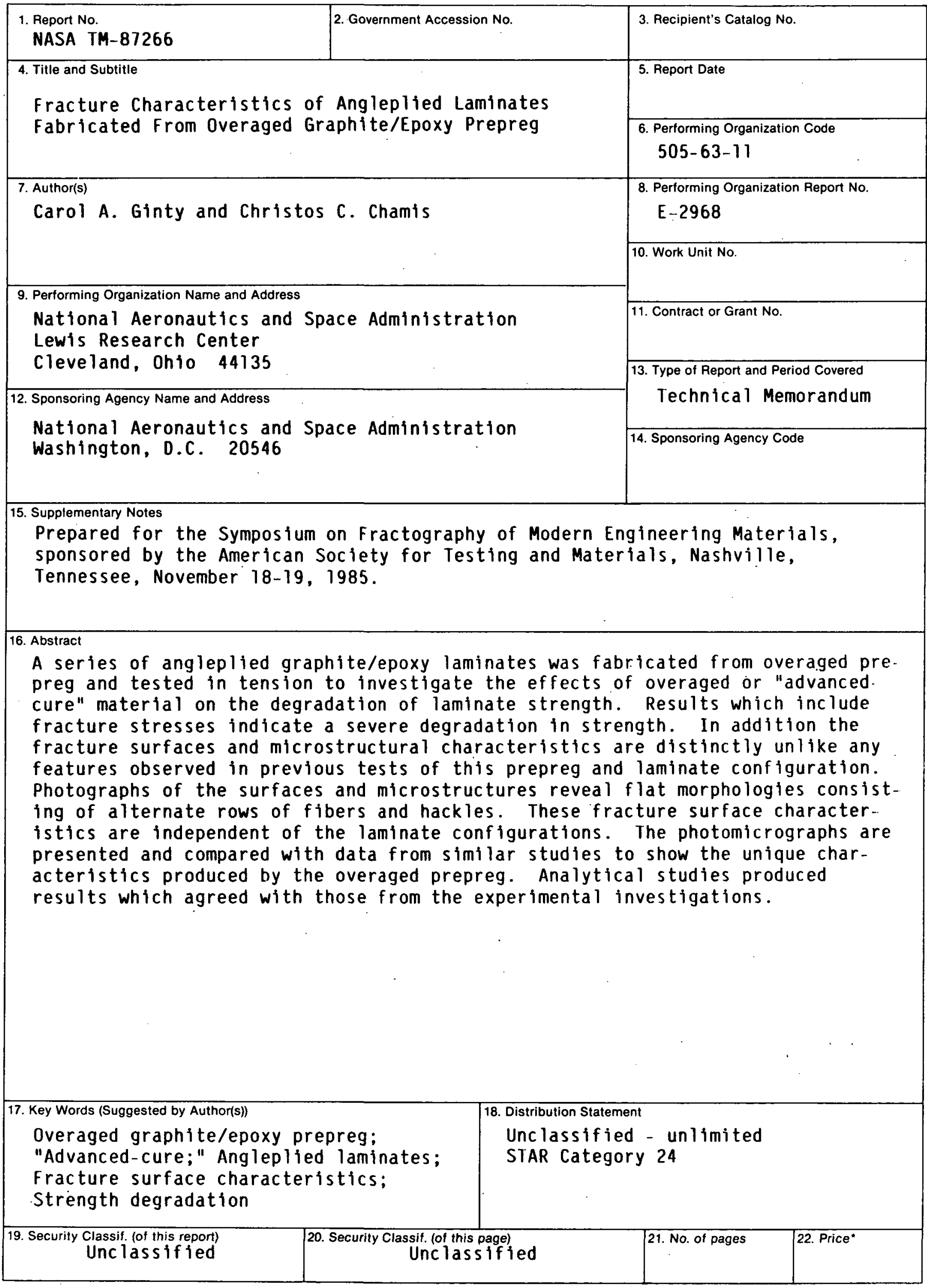

"For sale by the National Technical Information Service, Springfield, Virginia 22161 
National Aeronautics and Space Administration

Lewis Research Center

Cleveland. Ohio 44135

Official Business

Penally for Pitvate Use $\$ \mathbf{3 0 0}$
SECOND CLASS MAIL

ADDRESS CORRECTION REQUESTED

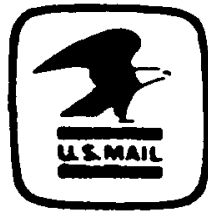

Postage and Fees Paid

National Aeronautics and

Space Administration

NASA-451 